\title{
Agreement and complementarity of sea ice drift products
}

\author{
A. Malin Johansson, and Anders Berg
}

\begin{abstract}
Changes in Arctic sea ice has raised questions about changes in sea ice drift patterns. Reduced sea ice coverage may open up the Arctic to further exploration of maritime activities, particularly during the summer months. Given such changes it is important to investigate differences between available sea ice drift products. Products based on synthetic aperture radar (SAR), radar scatterometer and radiometer are compared for both motion speed and direction within this study. Two Cband SAR and one L-band SAR product are used in the comparison. Differences in temporal and spatial resolutions of the drift estimates spanning from July 2010 until June 2011 are investigated. High temporal and spatial resolution was proven useful to fully capture the sea ice drift in the Fram Strait. For summer coverage, SAR data is a prerequisite and L-band is desirable.

The two C-band SAR products have a mean speed correlation of 0.90 and exhibit high conformity, despite being generated by separate processing methods. The L-band SAR product and the scatterometer and radiometer products are to a lower degree in agreement with each other and the $\mathrm{C}$-band SAR products, which may be attributed to the products' dependency on the temporal baseline. Depending on the choice of sensor or combination of sensors, the resulting twelve-month mean drift varies between 0.09 and $0.12 \mathrm{~m} / \mathrm{s}$ excluding L-band SAR. The latter shows a particularly low drift of $0.05 \mathrm{~m} / \mathrm{s}$, which we attribute to an overrepresentation of slow ice.
\end{abstract}

Index Terms-Remote Sensing, Sea ice, synthetic aperture radar, radiometry, time series

\section{INTRODUCTION}

$\mathbf{T}$ HE drift of sea ice is not only a central component needed to set up any description of sea ice dynamics, but is also essential to the fields of navigation, pollutant transport, and ice forcing on ships and other structures [15]. The ice drift is also a factor to consider in studies of climate change in the polar region. Satellite measurements show that the speed of the sea ice has been increasing in the Arctic over the last decade [19], [24], [23], and further increase is expected. There is thus a large interest in monitoring the sea ice drift in the Arctic, and satellite imagery is principally the only method available to cover such a vast region. The basic principal is to track the sea ice in sequential images acquired over the same area, typically using some type of cross-correlation technique. Passive microwave and multispectral instruments

Manuscript received June 24, 2015; revised October 7 and November 26, 2015; accepted December 12015.

A. M. Johansson is with the Department of Physics and Technology, University of Troms $\varnothing-$ The Arctic University of Norway, 9037 Troms $\varnothing$. (email: malin.johansson@uit.no) and also with the Department of Earth and Space Sciences, Chalmers University of Technology, 41296 Gothenburg, Sweden

A. Berg is with the Department of Earth and Space Sciences, Chalmers University of Technology, 41296 Gothenburg, Sweden have provided long-term measurements of ice drift. Noteworthy are the SSMR/SSMI/SSMIS data record that dates back to 1978 as well as the AVHRR (Advanced Very High Resolution Radiometer) data record that dates back to 1981 [12]. The radiometer data were later complemented with scatterometer [7] and Synthetic Aperture Radar (SAR) products. There is consequently a suite of ice drift products available today, from various sensors, processed with different algorithms and spatial and temporal sampling. Their conformity and relative accuracy to one-another and in-situ measurement is however not well known.

A few studies have compared measurements from one sensor against another, showing for instance a high agreement between results from scatterometer and passive microwave sensors, though with a slight advantage to the former [29], [8]. SAR-derived ice drift is generally seen as more accurate than measurements with passive microwave instruments [23]. Both methods are however frequently validated against ice buoy measurements [12], [10], [22], [17]. Moreover, SAR images acquired in different frequency bands are compared and combined to derive drift [14]. More comprehensive studies comparing ice drift products from many sensors are however missing. The effects of various temporal sampling is of interest in this perspective, especially considering regions with very dynamic drift conditions. A recent study [9] showed that the speed observed from satellite-based sensors with revisit times of 1-3 days is underestimated by 10-20\% compared to buoy measurements in the region of the Arctic transpolar drift, since the low temporal resolution is unable to resolve the full drift pattern. This study will look further at the effects from low temporal sampling, and also investigate the relative accuracies of available products.

\section{STUdy AREA}

In this study we investigate the sea ice drift within the Fram Strait. The areal extent investigated is from $12^{\circ} \mathrm{W}$ to $12^{\circ} \mathrm{E}$ and $77^{\circ} \mathrm{N}$ to $83^{\circ} \mathrm{N}$. It should be noted that the ALOS images do not fully cover this region since they have been acquired over an area slightly further west, from $14^{\circ} \mathrm{W}$ to $7^{\circ} \mathrm{E}$ and $76^{\circ} \mathrm{N}$ to $81^{\circ} \mathrm{N}$. The Fram Strait is located between Greenland and the Svalbard Archipelago (Fig. 1). It is the major connection between the Arctic Ocean and the waters south of the polar region. It has been estimated that about $90 \%$ of the sea ice that is exported from the Arctic is transported through the Fram Strait by the Eastern Greenland Current [20]. This estimated ice export is in the range of $0.07-0.16 * 10^{6} \mathrm{~m}^{3} / \mathrm{s}$, which represents an important part of the total Arctic Ocean sea ice 
budget. The major sea ice export occurs between October and April [23]. In this study the sea ice drift velocity from July 2010 until June 2011 is investigated. Fig. 1 shows that the distribution of SAR images is most dense in the central Fram Strait, which means that the statistics are most representative there.

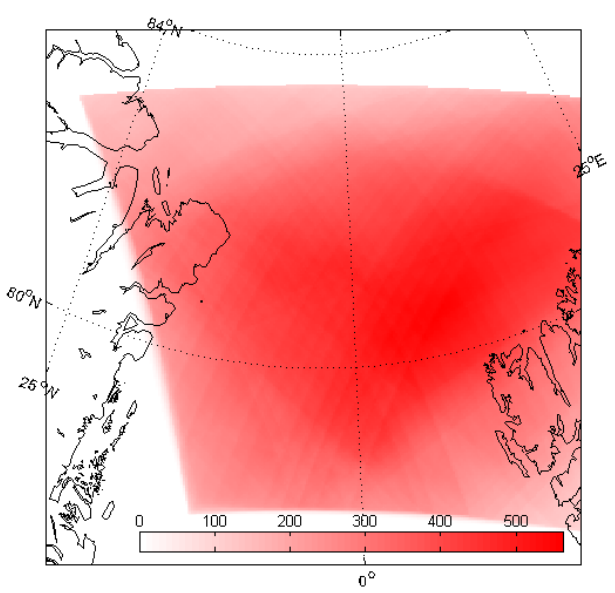

Fig. 1. Geographical distribution showing the number of overlaps between ASAR images.

\section{A. Ice and weather conditions}

The sea ice cover is highly dynamic and the sea ice drift is affected by surface winds and underlying ocean currents. Currents are a more important drift mechanism for thicker sea ice and thinner sea ice is more affected by wind stress. With the recent and expected continued thinning of the sea ice surface wind is expected to have an increased influence in the future. Surface wind affects the sea ice drift particularly on shorter time scales such as days and weeks.

The overall weather and sea ice conditions for the study period as outlined by [16] indicate that in July 2010, the weather was characterized by cyclones, i.e. low-pressure systems, in the central Arctic Ocean, promoting a cyclonic (anticlockwise) sea ice motion. High pressure conditions began in August, changing the Arctic Oscillation to its negative phase and to an anticyclonic (clockwise) transport pattern that lasted until February 2011. The 2010 minimum sea ice extent (Fig. 2) was reached with very low ice extent in the East Greenland Sea. The ice grew rapidly and reached its normal extent in late autumn. The year 2011 started with warm weather in the region, with as much as 5 to 7 degrees higher than normal temperatures in February. The ice coverage was relatively stable and unchanging during February and March. Then the melt onset came early, roughly two months earlier than the average date. The weather patterns favoured the export of sea ice through the Fram Strait during the summer, keeping the ice extent at the average level in the region, whereas lower than average extent could be observed in the rest of the Arctic. The year ended with four months predominantly in the positive phase of the Arctic Oscillation, supporting ice movement out of the Fram Strait to the North Atlantic.
Temperature data from Danmarkshavn, Greenland, indicated daily mean average temperatures below $0^{\circ} \mathrm{C}$ from September 5, 2010, to June 11, 2011, and with temperatures below the sea ice freezing temperature at $-1.8^{\circ} \mathrm{C}$ from September 18, 2010, to June 9, 2011.

\section{DATA SETS}

Sea ice drift estimates based on various types of satellite images processed with different algorithms are compared. The sea ice drift algorithms developed by [1] and [25] utilise Envisat C-band SAR data. Moreover, the algorithm developed by [1] has been tuned to handle ALOS PALSAR L-band data with their different spatial resolution and pixel spacing. Sea ice drift estimates by IFREMER and EumetCast \& OSI-SAF use scatterometer data from ASCAT or SeaWinds that also may be combined with SSM/I data. All images were located within the Fram Strait (Fig. 1). Supplementary data such as in-situ drift buoy data are used to evaluate the sea ice drift estimates.

\section{A. Satellite images}

1) SAR images: The SAR satellite images used in this study are wide swath SAR data from the two satellites Envisat and ALOS. The two SAR sensors collect data with different frequencies, the ASAR sensor onboard Envisat operates at C-band and the Palsar sensor onboard ALOS at L-band. A total of 260 Envisat images acquired from July 4, 2010 to June 29, 2011 were used in the study, as well as 29 ALOS images acquired from July 3, 2010 to March 23, 2011. The malfunctioning of the ALOS sensor in April 2011 meant that ALOS data from in total 9 months were used.

Envisat images with a time separation of roughly 22 hours are used for the comparison with the other sea ice drift products. Furthermore, Envisat images separated by $<22$ hours and $>26$ hours are used to study the influence of the temporal separation on the drift measurements. The ALOS images are separated by roughly 48 hours, with the exception of two out of four image pairs from July. The ALOS satellite primarily collect data over land areas and hence the majority of the images are situated closer to the east Greenland coast line.

Wide swath mode is preferred in sea ice monitoring due to the large spatial coverage. The Envisat images have a swath width of $400 \mathrm{~km}$ and a spatial resolution of 150x150 $\mathrm{m}$ at $7 \times 3$ looks (range vs azimuth). The swath width of the ALOS images is $350 \mathrm{~km}$ and these are processed with a spatial resolution of $100 \times 100 \mathrm{~m}$ at $4 \times 2$ looks. Horizontal copolarization $(\mathrm{HH})$ was used for all images, which is preferred for operational sea ice mapping [3]. The satellite images were geocoded to the Universal Transverse Mercator coordinate system using the WGS84 ellipsoid.

2) Radar scatterometer and radiometer data: The IFREMER products are based on radar scatterometer data [26]. The measurements consist of radar backscatter maps from Advanced Scatterometer (ASCAT) and SeaWinds. ASCAT is a C-band scatterometer that is carried by the MetOp-A satellite 

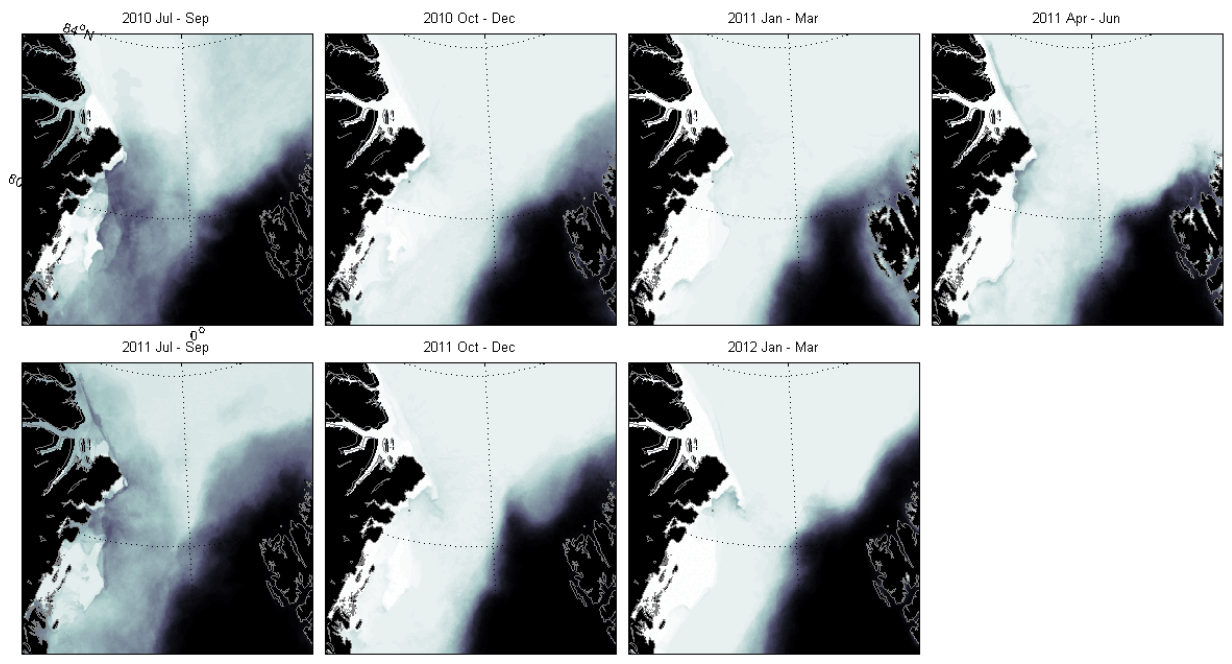

Fig. 2. Sea ice coverage from Norwegian Meteorological Institute covering a seasonal cycle.

that was launched in 2006, whereas SeaWinds is a Ku-band scatterometer on QuikSCAT, launched by NASA in 1999.

The EumetCast \& OSI-SAF product is based on ASCAT data together with radiometer data from Special Sensor Microwave Imager (SSM/I) or the Special Sensor Microwave Imager Sounder (SSMIS) [27]. SSM/I is a polarized passive microwave radiometer system carried onboard the Defense Meteorological Satellite Program (DMSP) satellites since 1987. It is a seven channel passive microwave radiometer operating at four frequences where 3 are dual pole and one is V-polarization only. SSM/I was replaced by SSMIS on the latter satellites within the program. Those satellites became operational in 2005, 2008 and 2010.

\section{B. Support data}

1) Drift buoy in-situ data: The Chalmers sea ice drift estimates from SAR images are compared with in-situ drift buoy data from the International Arctic Buoy Programme (IABP). The buoy data gives one position every 12 hours, i.e. two positions a day: one at midday and one at midnight UTC. Drift speed calculations using drift buoy data are made utilising different temporal resolution, 12, 24, 48 and 72 hours.

2) Sea ice charts: Comparison with sea ice charts from Met.no indicate that the images contain fast ice, very closely packed drift ice, closely packed drift ice, open drift drift ice, very open drift ice and open water. Although not all images contained all of the mentioned sea ice types. The drifting ice contained both large areas of compact ice and fields of smaller ice floes. Monthly averaged proportions of sea ice types were calculated in order to compare if certain sea ice types showed a better agreement between the sea ice drift products.

\section{Products}

Five different sea ice drift products were compared to the Chalmers sea ice drift product. The set of products constitute of one product from DTU, three different ones from IFREMER and one from EumetCast \& OSI-SAF. The drift speeds on 2011-01-07 are shown in Fig. 3.
1) Chalmers sea ice drift product: The Chalmers algorithm uses a hybrid method to track the ice, consisting of an area tracking module and a feature tracking module [1]. Areal tracking is performed using phase correlation, a frequencydomain approach to estimate the translational offset between two images. The images are processed in steps with increasing resolution, starting with down-sampled images in coarse resolution. In case of low correlation, a potential rotation is searched for and resolved. Feature tracking is performed by identification and tracking of ice floe boundaries in areas where individual floes are discernible.

2) DTU sea ice drift product: The DTU product $\left(\mathrm{SAR}_{D T U}\right)$ used Envisat ASAR WideSwath images until the satellite ceased its operations in April 2012. Since then, the Radarsat2 satellite is used instead [25]. Envisat ASAR data were resampled to $300 \mathrm{~m}$ resolution. The method used to track the sea ice is a brute force search for maximum crosscorrelation [21]. The retrieved motion field is filtered based on neighborhood similarity. The operational system processes all images that have overlapping areas and are separated in time by roughly 22 hours. The time separation range from 15 to 33 hours.

3) IFREMER sea ice drift products: For the IFREMER products the backscatter images are formed by averaging the backscatter for the different beams from one days acquisitions [6]. The result is an intermediate product, a composite map, which in the subsequent step is used to filter the image employing a Laplace filter. The Laplacian is computed because it brings out edges in the image and aids tracking of the ice. A median filter is applied to the resulting images, and the image from day 0 is then cross-correlated with the image from day 3. Cross-correlation is performed by correlating one image window from the first image with all the candidate image windows within a limited region in the second image. The ice motion vector is determined by the location of the image window that returns maximum cross-correlation. The IFREMER producs are based on ASCAT $\left(\mathrm{ASCAT}_{I F R}\right)$, ASCAT + SSMI (ASCAT+SSMI $I F R)$ and SeaWinds+SSMI 
a)

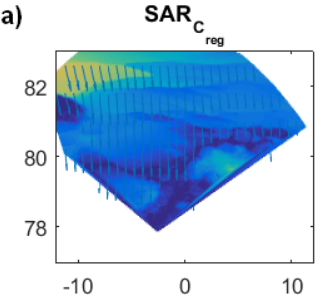

d)

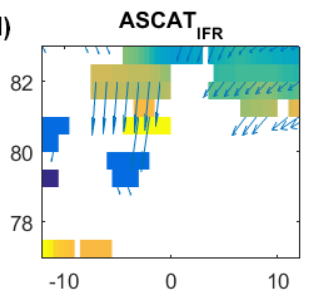

b)

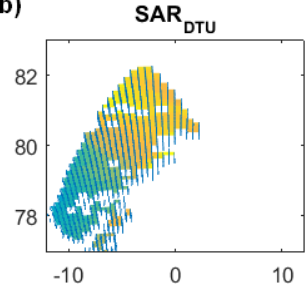

e)

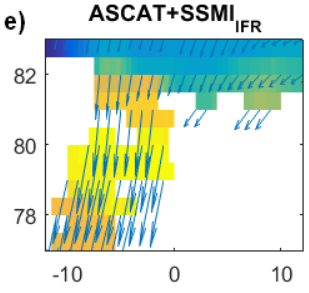

c)
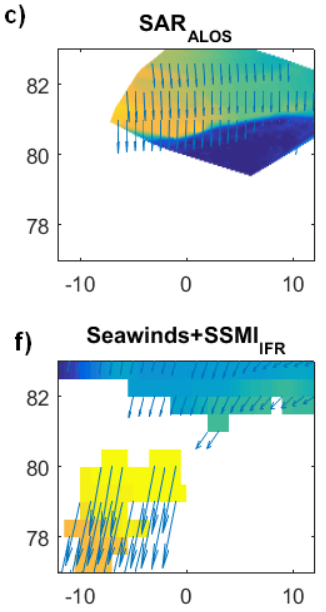

$\mathrm{m} / \mathrm{s}$

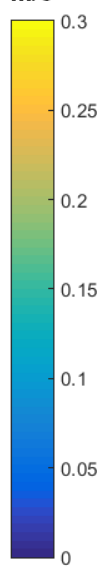

Fig. 3. Sea ice drift for the different drift products on 2011-01-07, a) $\mathrm{SAR}_{C_{r e g}}$, b) $\mathrm{SAR}_{D T U}$, c) $\mathrm{SAR}_{A L O S}$, d) $\mathrm{ASCAT}_{I F R}$, e) $\mathrm{ASCAT}_{\mathrm{SSSMI}} \mathrm{SFR}_{2}$, f) Seawinds $+\mathrm{SSMI}_{I F R}$ and $\left.\mathrm{g}\right) \mathrm{ASCAT}+\mathrm{SSMI} / \mathrm{S}_{E O}$.

(SeaWinds+SSMI $\left.I_{I F R}\right)$.

4) EumetCast \& OSI-SAF sea ice drift product: The daily average backscatter images for the EumetCast \& OSI-SAF product is based on ASCAT (ASCAT+SSMI/ $\mathrm{S}_{E O}$ ) data together with radiometer data from SSM/I or SSMIS [27]. The daily average backscatter images are computed as for the IFREMER products, and the Laplacian of those images is determined. The computation of the Laplacian is not approximated as for the IFREMER product, and no median filter is applied [13]. The maximum cross-correlation method is performed with interpolation of pixel values in order to achieve better accuracy and minimize quantization noise. The resulting motion field is processed with a filtering method that will correct vectors that deviate too much from the local mean drift. The motion field is computed separately for the sensors and merged into a daily product by weighted averaging, where the weights are inverse to the standard deviation associated to each sensor.

\section{Methods}

The comparison is performed using the Chalmers regular product $\left(\mathrm{SAR}_{C_{r e g}}\right)$ as the standard, followed by a focus on individual comparisons. Products from July 2010 until June 2011 were used in the comparison. This meant that both summer and winter conditions were investigated to evaluate if the results are sensitive to melt and freeze conditions.

The $\mathrm{SAR}_{D T U}, \quad \mathrm{ASCAT}_{I F R}, \quad \mathrm{ASCAT}+\mathrm{SSMI}_{I F R}$, SeaWinds $+\mathrm{SSMI}_{I F R}$ and $\mathrm{ASCAT}+\mathrm{SSMI} / \mathrm{S}_{E O}$ products are available for the whole Arctic and the Antarctic. However, for this comparison only data in the Fram Strait are used. The $\operatorname{ASCAT}_{I F R}, \mathrm{ASCAT}_{+} \mathrm{SSMI}_{I F R}$, SeaWinds+SSMI ${ }_{I F R}$ and ASCAT+SSMI $/ \mathrm{S}_{E O}$ products are only available from October to April, i.e. covers the season with the major sea ice export [23]. When there are 20 or less overlapping drift estimates between two sea ice drift products, such as between the $\mathrm{SAR}_{C_{\text {reg }}}$ product and the $\mathrm{SAR}_{D T U}$ product, these overlapping pairs are excluded from the study.

Three of the products $\left(\mathrm{SAR}_{C_{\text {reg }}}, \mathrm{SAR}_{C_{\text {low }}}\right.$ and $\left.\mathrm{SAR}_{D T U}\right)$ are based on SAR C-band images (Table I). These products are calculated using the same image pairs separated in time by on average 22 hours. The time separation range from 15 to 33 hours. The SAR $\mathrm{STU}_{D T}$ product is given on a regular grid with approximately $10 \mathrm{~km}$ resolution. The regular grid is adjusted to each image pair to enable the largest possible areal coverage. $\mathrm{SAR}_{C_{\text {reg }}}$ is down sampled from $1.5 \mathrm{~km}$ resolution onto the same regular grid as the $\mathrm{SAR}_{D T U}$ product. $\mathrm{SAR}_{C_{r e g}}$ is also calculated to the same regular grid as the $\mathrm{SAR}_{D T U}$ product, without a later down sampling. This product is from now on referred to as $\mathrm{SAR}_{C_{l o w}}$. Thus the fundamental resolution of

TABLE I

VARIOUS ATTRIBUTES OF THE ICE DRIFT DATA SETS

\begin{tabular}{|c|c|c|c|c|}
\hline Provider & Chalmers & DTU & IFREMER & EumetCast \& OSI-SAF \\
\hline Sensor & $\begin{array}{l}\text { Envisat ASAR, } \\
\text { ALOS PALSAR, } \\
\text { RadarSat-2 }\end{array}$ & $\begin{array}{l}\text { Envisat ASAR, } \\
\text { Radarsat-2 }\end{array}$ & $\begin{array}{l}\text { ASCAT, } \\
\text { ASCAT + SSM/I, } \\
\text { SeaWinds + SSM/I }\end{array}$ & $\begin{array}{l}\text { ASCAT }+ \\
\text { SSM/I or SSMIS }\end{array}$ \\
\hline Temporal resolution & $\begin{array}{l}22 \text { hours (Envisat) } \\
24 \text { and } 48 \text { hours (ALOS) }\end{array}$ & 22 hours & $\begin{array}{l}3 \text { days ( } 24 \mathrm{~h} \\
\text { averaged fields) }\end{array}$ & $\begin{array}{l}2 \text { days ( } 24 \mathrm{~h} \\
\text { averaged fields) }\end{array}$ \\
\hline Spatial resolution & $1.5 \mathrm{~km}$ & $10.2 \mathrm{~km}$ & 0.5 degree & $62.5 \mathrm{~km}$ \\
\hline Grid & Lat/lon grid & $\begin{array}{l}\text { Polar stereographic, } \\
\text { true at } 70 \mathrm{~N}\end{array}$ & $\begin{array}{l}\text { Regular lat/lon } \\
\text { grid }\end{array}$ & $\begin{array}{l}\text { Polar stereographic, } \\
\text { true at } 70 \mathrm{~N}\end{array}$ \\
\hline
\end{tabular}


the motion field of the two products will be the same. It can be noted however that $\mathrm{SAR}_{C_{\text {low }}}$ is computed from full-resolution images, whereas $\mathrm{SAR}_{D T U}$ is computed from images that are multilooked by a factor two. Basically, $\mathrm{SAR}_{C_{l o w}}$ is introduced to enable evaluation of whether any dissimilarities arise from the resolution or differences in the algorithm.

The sea ice drift estimates from $\operatorname{ASCAT}_{I F R}$, $\mathrm{ASCAT}+\mathrm{SSMI}_{I F R}$ and SeaWinds $+\mathrm{SSMI}_{I F R}$ has a 3 day temporal resolution with a center at 00:00 am on day 3. The ASCAT+SSMI/S $\mathrm{S}_{E O}$ product have a 2 day temporal resolution. The comparison is made on day 3 of the $\mathrm{ASCAT}_{I F R}, \quad \mathrm{ASCAT}_{\mathrm{SSSMI}} \mathrm{SFR}_{I F}$ and SeaWinds+SSMI $I F R$ products and on day 2 for the ASCAT+SSMI/S $\mathrm{S}_{E O}$ product. $\mathrm{SAR}_{C_{\text {reg }}}$ is down sampled from $1.5 \mathrm{~km}$ resolution onto the same regular grid as the $\mathrm{ASCAT}_{I F R}, \mathrm{ASCAT}+\mathrm{SSMI}_{I F R}$, SeaWinds $+\mathrm{SSMI}_{I F R}$ and ASCAT+SSMI/S $\mathrm{S}_{E O}$ products for the comparison with those products (Table I). Monthly mean speeds are calculated using the sea ice drift products original grid. The drift speeds on 2011-01-07 are shown in Fig. 3.

The ice speed is evaluated in terms of median ice speed ratio between the drift products and $\mathrm{SAR}_{C_{r e g}}$. Median is selected instead of mean in order to eliminate the effect of outliers, such as on the border between two displacement zones where one product may favor for instance a motionless solution and the other a drifting ice solution. The median will show how well the products agree for typical operation within displacement zones. The ratio is computed instead of an absolute bias to give weight for deviations also at lower speeds. The median is determined on a monthly basis to dissolve possible seasonal variations. Besides the comparison to $\mathrm{SAR}_{C_{r e g}}$, the $\mathrm{SAR}_{D T U}$ product is also compared to the $\mathrm{SAR}_{C_{l o w}}$ product.

The same approach is used for direction, i.e. monthly mean directional differences is computed. We compute the mean direction, following [18], as the direction of the resultant vector that is formed by converting each measured direction to its rectangular form $\left(\cos \theta_{i}, \sin \theta_{i}\right), i=1, \ldots, n$ and summing them component-wise. In this way the wrap-around effect is taken care of. We also study the monthly mean correlation and speed values. The $\mathrm{SAR}_{C_{r e g}}$ product is separated into 3 different temporal resolution, $<22$ hours, 22-26 hours and $>26$ hours. This enables comparisons about the effect of temporal resolution and how it affects the speed captured and the direction. Correlation between all the different products is also calculated for both speed and direction.

In-situ buoy data are compared with $\mathrm{SAR}_{C_{r e g}}$. Drift buoy data is included in the analysis if the position is within 10 $\mathrm{km}$ of the closest available $\mathrm{SAR}_{C_{r e g}}$ coordinate during the time period between the first and the second image in the used image pair. Combined this implies that 30 image pairs were to in-situ buoy data. Drift buoy trajectories were averaged over 24, 48 and 72 hours $\left(\mathrm{Vel}_{24}, \mathrm{Vel}_{48}\right.$ and $\left.\mathrm{Vel}_{72}\right)$. This corresponds approximately to the time separation between the different satellite images used for the drift speed estimates. For example, the ratio of $\mathrm{Vel}_{48}$ and $\mathrm{Vel}_{24}$ should give an indication on the difference in speed that is to be expected between the $\mathrm{ASCAT}+\mathrm{SSMI} / \mathrm{S}_{E O}$ product compared to the $\mathrm{SAR}_{C_{r e g}}$ and $\mathrm{SAR}_{D T U}$ products.

\section{RESUlts}

\section{A. Drift speed comparison}

The monthly median speed ratios are presented in Table II. There is good agreement between the two C-band SAR based products $\left(\mathrm{SAR}_{C_{r e g}}\right.$ and $\left.\mathrm{SAR}_{D T U}\right)$, where the $\mathrm{SAR}_{C_{r e g}}$ drift speeds are just slightly above the corresponding $\mathrm{SAR}_{D T U}$ drift speeds. The speed correlation values between these two products are above 0.84 for all months, with a yearly mean value of 0.9 (Table III).

Including $\mathrm{SAR}_{C_{\text {low }}}$ in the comparison shows that also this product agrees well with the $\mathrm{SAR}_{D T U}$ product when it comes to ice speed. Correlation values are generally high, above 0.75 , with the month of July, 2010, being an exception. This month both Chalmers products have considerably slower ice than the $\mathrm{SAR}_{D T U}$ product, especially $\mathrm{SAR}_{C_{\text {low }}}$ stands out with a

TABLE II

MONTHLY MEDIAN SPEED RATIO BETWEEN THE SEVEN DIFFERENT PRODUCTS AND SAR $C_{r e g}$.

\begin{tabular}{|c|c|c|c|c|c|c|c|c|}
\hline Month & $\begin{array}{l}\mathbf{S A R}_{D T U} / \\
\mathbf{S A R}_{C_{r e g}}\end{array}$ & $\begin{array}{l}\mathbf{S A R}_{D T U} / \\
\mathbf{S A R}_{C_{\text {low }}}\end{array}$ & $\begin{array}{l}\mathbf{A S C A T}_{I F R} / \\
\mathbf{S A R}_{C_{r e g}}\end{array}$ & $\begin{array}{l}\text { ASCAT+ } \\
\text { SSMI }_{I F R} / \\
\text { SAR }_{C_{r e g}} \\
\end{array}$ & $\begin{array}{l}\text { SeaWinds+ } \\
\text { SSMI }_{I F R} / \\
\text { SAR }_{C_{r e g}}\end{array}$ & $\begin{array}{l}\text { ASCAT+ } \\
\text { SSMI/S }_{E O} / \\
\text { SAR }_{C_{r e g}} \\
\end{array}$ & $\begin{array}{l}\mathbf{S A R}_{A L O S} / \\
\mathbf{S A R}_{C_{r e g}}\end{array}$ & $\begin{array}{l}\text { Buoy/ } \\
\text { SAR }_{C_{r e g}}\end{array}$ \\
\hline July & $0.92 \pm 0.94$ & $0.74 \pm 0.19$ & - & - & - & - & $0.68 \pm 272.84$ & - \\
\hline Aug & $0.97 \pm 0.57$ & $0.97 \pm 0.08$ & - & - & - & - & $0.98 \pm 26.97$ & - \\
\hline Sept & $0.96 \pm 0.87$ & $0.96 \pm 0.78$ & - & - & - & - & $0.96 \pm 4.75$ & $1.12 \pm 0.50$ \\
\hline Oct & $0.98 \pm 0.74$ & $0.98 \pm 0.14$ & $0.65 \pm 1.23$ & $0.94 \pm 1.59$ & $0.97 \pm 1.48$ & $1.22 \pm 0.97$ & - & $1.07 \pm 0.62$ \\
\hline Nov & $0.97 \pm 0.12$ & $0.98 \pm 0.33$ & $0.82 \pm 0.69$ & $0.88 \pm 1.00$ & $0.87 \pm 1.02$ & $0.85 \pm 0.41$ & - & $0.71 \pm 0.96$ \\
\hline Dec & $0.98 \pm 0.40$ & $0.98 \pm 0.06$ & $0.56 \pm 2.59$ & $0.68 \pm 7.22$ & $0.68 \pm 7.60$ & $0.83 \pm 5.36$ & $0.20 \pm 6.46$ & $1.26 \pm 0.55$ \\
\hline Jan & $0.97 \pm 0.23$ & $0.97 \pm 0.19$ & $1.61 \pm 17.03$ & $1.83 \pm 17.03$ & $1.99 \pm 17.00$ & $1.52 \pm 2.22$ & $0.26 \pm 4.49$ & $1.02 \pm 0.39$ \\
\hline Feb & $0.97 \pm 0.32$ & $0.97 \pm 0.29$ & $1.05 \pm 2.86$ & $1.01 \pm 1.58$ & $1.02 \pm 1.56$ & $1.19 \pm 0.90$ & - & $1.18 \pm 0.93$ \\
\hline March & $0.98 \pm 1.09$ & $1.00 \pm 0.10$ & $0.93 \pm 25.54$ & $1.10 \pm 18.40$ & $1.24 \pm 16.52$ & $1.79 \pm 21.96$ & $0.22 \pm 5.23$ & - \\
\hline April & $0.97 \pm 1.73$ & $0.97 \pm 0.11$ & $0.78 \pm 2.61$ & $0.85 \pm 2.48$ & $0.97 \pm 2.10$ & $0.98 \pm 0.78$ & - & - \\
\hline May & $0.97 \pm 4.28$ & $0.97 \pm 0.13$ & - & - & - & - & - & - \\
\hline June & $0.97 \pm 0.55$ & $0.96 \pm 0.17$ & - & - & - & - & - & - \\
\hline Mean & 0.97 & 0.97 & 0.82 & 0.94 & 0.97 & 1.19 & 0.47 & 1.06 \\
\hline
\end{tabular}


TABLE III

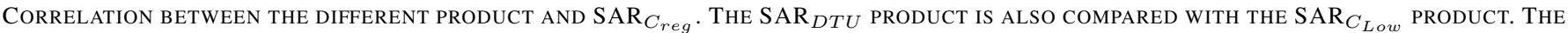
CORRELATION IS CALCULATED USING THE SPEED. THE VALUES ARE PRESENTED AS MEAN MONTHLY CORRELATION VALUES.

\begin{tabular}{|c|c|c|c|c|c|c|c|}
\hline Month & $\mathbf{S A R}_{D T U}$ & $\begin{array}{l}\mathbf{S A R}_{D T U} \text { vs. } \\
\mathbf{S A R}_{C_{L o w}}\end{array}$ & $\mathbf{A S C A T}_{I F R}$ & $\begin{array}{l}\text { ASCAT+ } \\
\text { SSMI }_{I F R}\end{array}$ & $\begin{array}{l}\text { SeaWinds+ } \\
\text { SSMI }_{I F R}\end{array}$ & $\begin{array}{l}\text { ASCAT+ } \\
\text { SSMI/S }_{E O}\end{array}$ & $\mathbf{S A R}_{A L O S}$ \\
\hline July & 0.85 & 0.69 & - & - & - & - & 0.27 \\
\hline Aug & 0.84 & 0.91 & - & - & - & - & 0.16 \\
\hline Sept & 0.86 & 0.75 & - & - & - & - & 0.17 \\
\hline Oct & 0.90 & 0.96 & 0.47 & 0.39 & 0.40 & 0.38 & - \\
\hline Nov & 0.97 & 0.79 & 0.61 & 0.50 & 0.48 & 0.55 & - \\
\hline Dec & 0.89 & 0.92 & 0.53 & 0.29 & 0.18 & 0.26 & 0.27 \\
\hline Jan & 0.91 & 0.94 & 0.36 & 0.32 & 0.27 & 0.56 & 0.41 \\
\hline Feb & 0.94 & 0.81 & 0.41 & 0.73 & 0.73 & 0.63 & - \\
\hline March & 0.88 & 0.98 & 0.37 & 0.51 & 0.55 & 0.32 & 0.39 \\
\hline April & 0.95 & 0.91 & 0.33 & 0.23 & 0.18 & 0.18 & - \\
\hline May & 0.91 & 0.83 & - & - & - & - & - \\
\hline June & 0.87 & 0.81 & - & - & - & - & - \\
\hline Mean & 0.90 & 0.86 & 0.44 & 0.42 & 0.40 & 0.41 & 0.28 \\
\hline
\end{tabular}

median speed ratio of 0.74 and a corresponding correlation value of 0.69 (Table III).

The mean speed values for the three C-band SAR based products (Table IV) are of the same order of magnitude, whereas the variation in drift speed over a month is larger for the $\mathrm{SAR}_{D T U}$ and $\mathrm{SAR}_{C_{\text {low }}}$ than the $\mathrm{SAR}_{C_{\text {reg }}}$. Comparing mean speed for the C-band images indicate that sea ice drifts estimates for satellite images separated by $>26$ hours have lower mean speeds than the images with $<22$ hours time separation (Fig. 4a). Similarly are the mean speed values for the 22-26 hours time separation lower than the values for the images separated by $<22$ hours. The only months when a shorter time separation between the images does not imply higher mean monthly speed values are for September and February.

The $\mathrm{ASCAT}_{I F R}, \quad \mathrm{ASCAT}+\mathrm{SSMI}_{I F R}$ and SeaWinds $+\operatorname{SSMI}_{I F R}$ products have more often lower mean velocities than the $\mathrm{SAR}_{C_{\text {reg }}}$ products (Table IV). There

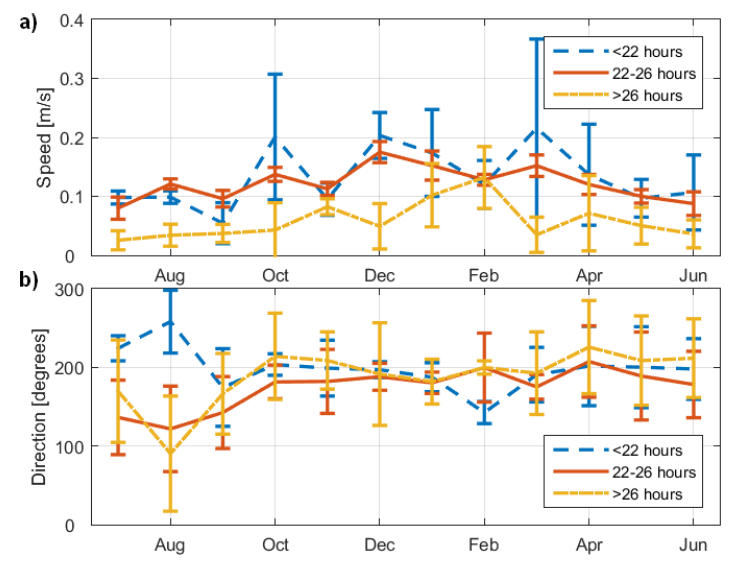
is however a period from January to March that is an exception

Fig. 4. a) Monthly mean speed (m/s) for the $\mathrm{SAR}_{C_{r e g}}$ with different time span between the used Envisat images, b) Monthly mean direction (degrees) for the $\mathrm{SAR}_{C_{r e g}}$ with different time span between the used Envisat images.

TABLE IV

MONTHLY MEAN SPEED (M/S) FOR THE EIGHT DIFFERENT PRODUCTS.

\begin{tabular}{|c|c|c|c|c|c|c|c|c|c|}
\hline Month & $\mathbf{S A R}_{C_{r e g}}$ & $\mathbf{S A R}_{D T U}$ & $\mathbf{S A R}_{C_{l o w}}$ & $\operatorname{ASCAT}_{I F R}$ & $\begin{array}{l}\text { ASCAT+ } \\
\text { SSMI }_{I F R}\end{array}$ & $\begin{array}{l}\text { SeaWinds+ } \\
\text { SSMI }_{I F R}\end{array}$ & $\begin{array}{l}\text { ASCAT+ } \\
\text { SSMI/S }_{E O}\end{array}$ & $\mathbf{S A R}_{A L O S}$ & Buoy \\
\hline July & $0.08 \pm 0.02$ & $0.06 \pm 0.04$ & $0.03 \pm 0$ & - & - & - & - & $0.04 \pm 0.02$ & - \\
\hline Aug & $0.12 \pm 0.01$ & $0.11 \pm 0.05$ & $0.11 \pm 0.05$ & - & - & - & - & $0.05 \pm 0.03$ & - \\
\hline Sept & $0.10 \pm 0.01$ & $0.10 \pm 0.04$ & $0.08 \pm 0.05$ & - & - & - & - & $0.02 \pm 0.02$ & $0.11 \pm 0.06$ \\
\hline Oct & $0.14 \pm 0.01$ & $0.11 \pm 0.04$ & $0.10 \pm 0.02$ & $0.08 \pm 0.02$ & $0.08 \pm 0.03$ & $0.08 \pm 0.03$ & $0.12 \pm 0.04$ & - & $0.14 \pm 0.07$ \\
\hline Nov & $0.11 \pm 0.01$ & $0.11 \pm 0.04$ & $0.11 \pm 0.09$ & $0.09 \pm 0.04$ & $0.09 \pm 0.04$ & $0.09 \pm 0.04$ & $0.10 \pm 0.03$ & - & $0.08 \pm 0.05$ \\
\hline Dec & $0.18 \pm 0.02$ & $0.14 \pm 0.05$ & $0.13 \pm 0.02$ & $0.09 \pm 0.04$ & $0.10 \pm 0.04$ & $0.10 \pm 0.04$ & $0.13 \pm 0.03$ & $0.05 \pm 0.04$ & $0.18 \pm 0.09$ \\
\hline Jan & $0.15 \pm 0.02$ & $0.13 \pm 0.05$ & $0.13 \pm 0.05$ & $0.07 \pm 0.03$ & $0.08 \pm 0.04$ & $0.08 \pm 0.04$ & $0.12 \pm 0.03$ & $0.07 \pm 0.06$ & $0.13 \pm 0.05$ \\
\hline Feb & $0.13 \pm 0.01$ & $0.11 \pm 0.07$ & $0.14 \pm 0.09$ & $0.10 \pm 0.04$ & $0.10 \pm 0.04$ & $0.11 \pm 0.05$ & $0.10 \pm 0.04$ & - & $0.07 \pm 0.03$ \\
\hline March & $0.15 \pm 0.02$ & $0.14 \pm 0.06$ & $0.16 \pm 0.01$ & $0.13 \pm 0.05$ & $0.13 \pm 0.05$ & $0.13 \pm 0.05$ & $0.15 \pm 0.04$ & $0.10 \pm 0.04$ & - \\
\hline April & $0.12 \pm 0.02$ & $0.10 \pm 0.06$ & $0.12 \pm 0.04$ & $0.06 \pm 0.02$ & $0.07 \pm 0.02$ & $0.11 \pm 0.02$ & $0.07 \pm 0.04$ & - & - \\
\hline May & $0.10 \pm 0.01$ & $0.09 \pm 0.04$ & $0.09 \pm 0.03$ & - & - & - & - & - & - \\
\hline June & $0.09 \pm 0.02$ & $0.08 \pm 0.04$ & $0.08 \pm 0.02$ & - & - & - & - & - & - \\
\hline Mean & 0.12 & 0.11 & 0.11 & 0.09 & 0.09 & 0.09 & 0.12 & 0.05 & 0.12 \\
\hline
\end{tabular}


TABLE V

CORRELATION BETWEEN THE DIFFERENT PRODUCTS FOR THE MONTH OF OCTOBER. THE CORRELATION IS CALCULATED USING THE SPEED.

\begin{tabular}{|c|c|c|c|c|c|c|}
\hline & $\mathbf{S A R} \mathbf{R}_{r e g}$ & $\mathbf{S A R}_{D T U}$ & $\mathbf{A S C A T}_{I F R}$ & $\begin{array}{l}\text { ASCAT+ } \\
\text { SSMI }_{I F R}\end{array}$ & $\begin{array}{l}\text { SeaWinds+ } \\
\text { SSMI }_{I F R}\end{array}$ & $\begin{array}{l}\text { ASCAT+ } \\
\text { SSMI/S }_{E O}\end{array}$ \\
\hline $\mathbf{S A R}_{C_{r e g}}$ & - & 0.90 & 0.47 & 0.39 & 0.40 & 0.38 \\
\hline $\mathbf{S A R}_{D T U}$ & 0.90 & - & 0.54 & 0.60 & 0.57 & 0.42 \\
\hline $\mathbf{A S C A T}_{I F R}$ & 0.47 & 0.54 & - & 0.47 & 0.31 & 0.47 \\
\hline $\mathbf{A S C A T}_{+} \mathbf{S S M I} \mathbf{I}_{I F R}$ & 0.39 & 0.60 & 0.47 & - & 0.92 & 0.47 \\
\hline SeaWinds+SSMI $_{I F R}$ & 0.40 & 0.57 & 0.31 & 0.92 & - & 0.50 \\
\hline $\mathbf{A S C A T}+\mathbf{S S M I} / \mathbf{S}_{E O}$ & 0.38 & 0.42 & 0.47 & 0.47 & 0.50 & - \\
\hline
\end{tabular}

- for this period the speed ratio was generally above 1 for the $\operatorname{ASCAT}_{I F R}, \quad$ ASCAT+SSMI $I F R$ and SeaWinds $+\mathrm{SSMI}_{I F R}$ products.

The ASCAT+SSMI $/ \mathrm{S}_{E O}$ drift speed values are on average higher than for $\mathrm{SAR}_{C_{r e g}}$, but the spread is large with three months out of seven that actually show slower drift (Table II). The ASCAT+SSMI $/ \mathrm{S}_{E O}$ mean speed values are similar to the C-band SAR drift speed estimates, whilst the $\operatorname{ASCAT}_{I F R}$, ASCAT $+\mathrm{SSMI}_{I F R}$ and SeaWinds $+\mathrm{SSMI}_{I F R}$ products have the lowest mean speeds apart from for February 2011.

Correlation values between the different products regarding speed indicate that there is a higher correlation between the $\mathrm{SAR}_{D T U} \mathrm{C}$-band SAR product and the $\mathrm{ASCAT}_{I F R}+\mathrm{SSMI} / \mathrm{S}_{E O}$ and SeaWinds $+\mathrm{SSMI}_{I F R}$ products than the C-band $\mathrm{SAR}_{C_{r e g}}$ product (Table V). Furthermore, the ASCAT SSMI product is in closer agreement with the $\mathrm{SAR}_{D T U}$ product than the other $\mathrm{ASCAT}_{I F R}$, ASCAT $+\mathrm{SSMI}_{I F R}$ and SeaWinds $+\mathrm{SSMI}_{I F R}$ products. For $\mathrm{SAR}_{C_{r e g}}$ the $\mathrm{ASCAT}_{I F R}$ product is the one of the IFREMER products that is in closest agreement. The ASCAT $+\mathrm{SSMI} / \mathrm{S}_{E O}$ product has a higher correlation with the $\operatorname{ASCAT}_{I F R}$, $\mathrm{ASCAT}+\mathrm{SSMI}_{I F R}$ and SeaWinds+SSMI $I F R$ products than with any of the C-band SAR based products.

TABLE VI

QUOTIENT OF THE AVERAGE SPEEDS.

$\begin{array}{ll}\mathrm{Vel}_{48} / \mathrm{Vel}_{24} & 0.91 \\ \mathrm{Vel}_{72} / \mathrm{Vel}_{24} & 0.85 \\ \mathrm{ASCAT}_{\mathrm{SSMI}} / \mathrm{S}_{E O} / \mathrm{SAR}_{C_{r e g}} & 0.96 \\ \mathrm{ASCAT}_{I F R} / \mathrm{SAR}_{C_{r e g}} & 0.73 \\ \mathrm{SeaWinds}_{\mathrm{SSSMI}} / \mathrm{SAR}_{C_{r e g}} & 0.77\end{array}$

The ALOS ( $\left.\mathrm{SAR}_{A L O S}\right)$ results are based on fewer satellite image pairs than the other products, 27 in total. Hence the results should be treated with caution. The monthly median ratios are for the months of August and September comparable with the C-band data (Table II). The L-band SAR drift speeds are lower than the other sea ice drift products. The ALOS images are confined to the east Greenland coast and have a different sea ice type distribution than the other sea ice drift products (Fig. 5a and b). Moreover, [14] argue that multi-year ice inclusions as well as sea ice concentrations below $60 \%$ may affect the L-band estimates unfavourably.

In-situ drift buoy mean speeds are in agreement with Cband SAR based estimates for most of the study period from September to February (Table IV). Values for November and February are deviating somewhat, showing slower drift than the C-band estimates. This is also reflected in the month of November having the lowest median speed ratio. No overlapping data was found for late spring and summer (from March to August). Average buoy velocities using a temporal baselines of $12\left(\mathrm{Vel}_{12}\right), 24\left(\mathrm{Vel}_{24}\right), 48\left(\mathrm{Vel}_{48}\right)$ and $72\left(\mathrm{Vel}_{72}\right)$ hours are determined, thereby accounting for the longer temporal baselines of the satellite-based products. The 72 hour time separation corresponds to the time separation for

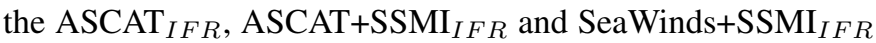
products and the 48 hour time separation corresponds to the ASCAT+SSMI/S $\mathrm{S}_{E O}$ product. The quotient of the average buoy speeds as well as the average sea ice drift products divided by $\mathrm{SAR}_{C_{\text {reg }}}$ are presented in Table VI.

\section{B. Drift direction comparison}

The mean directional difference between the $\mathrm{SAR}_{D T U}$ and $\mathrm{SAR}_{C_{r e g}}$ data are within 6.7 degrees (Table VII). For $\mathrm{SAR}_{C_{\text {low }}}$ the directional difference is within 9.6 degrees compared to $\mathrm{SAR}_{D T U}$. For the $\mathrm{ASCAT}_{I F R}, \mathrm{ASCAT}+\mathrm{SSMI}_{I F R}$ and SeaWinds $+\mathrm{SSMI}_{I F R}$ products the directional difference ranges up to 50.4 degrees. The $\mathrm{ASCAT}+\mathrm{SSMI} / \mathrm{S}_{E O}$ product have a directional difference compared to the $\mathrm{SAR}_{C_{\text {reg }}}$ that goes up to 149.1 degrees.

The directional correlation between the $\mathrm{SAR}_{C_{r e g}}$ and the $\mathrm{ASCAT}_{I F R}, \mathrm{ASCAT}+\mathrm{SSMI}_{I F R}, \quad$ SeaWinds+SSMI ${ }_{I F R}$ and ASCAT+SSMI $/ \mathrm{S}_{E O}$ products are of the same order of magnitude (Table VIII). The correlation between the $\mathrm{SAR}_{D T U}$ data and the $\mathrm{ASCAT}_{I F R}, \mathrm{ASCAT}+\mathrm{SSMI}_{I F R}$, SeaWinds $+\mathrm{SSMI}_{I F R}$ and ASCAT+SSMI/S $\mathrm{S}_{E O}$ products are lower than the $\mathrm{SAR}_{C_{\text {reg }}}$ directional correlation values.

\section{Sea ice type difference}

For the C-band SAR overlapping areas there is a low percentage of fast ice throughout the year (Fig. 5a). There is a change in sea ice type distribution between September and October - before October there was a larger distribution of different types of sea ice. Very close drift ice is the dominant type of sea ice for October to June. Open water is present in $\sim 23-27 \%$ for November until June. Between July and October the open water covers on average $34-35 \%$ of the overlapping images.

On account of an average location closer to the east Greenland coast sea ice type within the overlapping L-band SAR 
a)

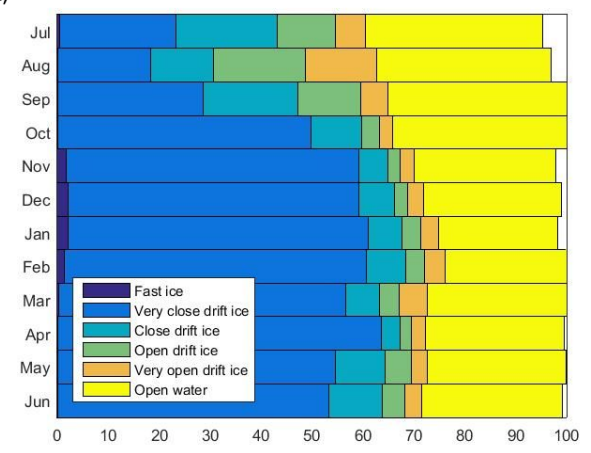

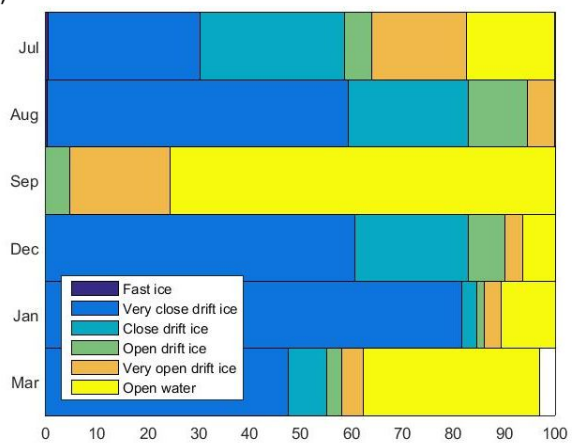

Fig. 5. Monthly average sea ice types for the overlapping a) Envisat images and b) ALOS images

images is determined. For the $\mathrm{SAR}_{A L O S}$ sea ice there are large discrepancies in the amount of different types of sea ice for the different months (Fig. 5b). The September images have $75 \%$ open water. August and December have similar sea ice type distribution and the same monthly mean speeds (Table IV).

\section{DISCUSSION}

A comparison between different sea ice drift algorithms was performed. Differences in both algorithm and sensor types were tested. The products have different spatial resolution as well as different temporal resolution.

\section{A. Product comparison}

The two C-band SAR products, SAR $_{D T U}$ and the SAR $_{C_{r e g}}$ have the closest resemblance with correlation values above 0.84 for all months (Table III) as well as monthly median speed ratios between 0.9 and 1.0 , with 0.97 being the most frequent value (Table II). The source of this relative speed difference is unknown, but considering its constancy it may be related to differences in the algorithms or the projection set-up. Comparison with buoy speeds favour the higher speeds of the
$\mathrm{SAR}_{C_{\text {reg }}}$ product, but the variability is too large to draw any definite conclusions about the source of this inconsistency (Table IV). The correlation between the $\mathrm{SAR}_{D T U}$ product and the $\mathrm{ASCAT}_{I F R}, \quad \mathrm{ASCAT}+\mathrm{SSMI}_{I F R}, \quad$ SeaWinds+SSMI $I F R$ and ASCAT+SSMI/S $E O$ products is higher than the comparative $\mathrm{SAR}_{C_{r e g}}$ correlation values (Table V and III). Looking at the speed correlations for the entire year (Table III) we see that each product has a mean correlation with a monthly variation that is moderate about the mean value. The difference in mean correlation between the products are relatively large in comparison to this variation, which suggests that the products can be reliably grouped based on correlation. It is very difficult to determine quantitatively the effect of e.g. temporal sampling on these correlation measurements, but it is probably large, considering that products from the same sensor type, or products generated with different algorithms on the same data only show minor differences. Closer examination of the $\operatorname{ASCAT}_{I F R}, \mathrm{ASCAT}+\mathrm{SSMI}_{I F R}$, SeaWinds+SSMI ${ }_{I F R}$ and $\mathrm{SAR}_{C_{r e g}}$ data from e.g. January (Table II) indicate a difference in the location of an area with higher drift values. This shift in location appear to be the reason for the higher monthly median speed ratio for this month. We believe that

TABLE VII

MONTHLY MEAN DIRECTIONAL DIFFERENCE IN DEGREES BETWEEN THE SEVEN DIFFERENT PRODUCTS AND SAR $C_{r e g}$. THE SAR $D T U$ PRODUCT IS ALSO COMPARED WITH THE SAR $C_{L o w}$ PRODUCT.

\begin{tabular}{l|ll|lll|l|l} 
Month & $\mathbf{S A R}_{D T U}$ & $\begin{array}{l}\mathbf{S A R}_{D T U} \text { vs. } \\
\mathbf{S A R}_{C_{l o w}}\end{array}$ & $\mathbf{A S C A T}_{I F R}$ & $\begin{array}{l}\text { ASCAT+ } \\
\mathbf{S S M I}_{I F R}\end{array}$ & $\begin{array}{l}\text { SeaWinds+ } \\
\mathbf{S S M I}_{I F R}\end{array}$ & $\begin{array}{l}\text { ASCAT+ } \\
\mathbf{S S M I}_{E O}\end{array}$ & $\mathbf{S A R}_{A L O S}$ \\
\hline July & $3.77 \pm 9.53$ & $-8.40 \pm 0$ & - & - & - & - & $-6.76 \pm 52.87$ \\
Aug & $-0.94 \pm 6.69$ & $1.53 \pm 5.82$ & - & - & - & - & $-71.00 \pm 63.63$ \\
\hline Sept & $-0.03 \pm 6.27$ & $3.78 \pm 4.85$ & - & - & - & - & $-18.94 \pm 0$ \\
Oct & $4.82 \pm 7.28$ & $8.97 \pm 2.55$ & $14.60 \pm 56.93$ & $21.02 \pm 24.45$ & $21.13 \pm 23.76$ & $40.50 \pm 13.08$ & - \\
Nov & $-2.24 \pm 9.85$ & $6.72 \pm 1.62$ & $-9.56 \pm 62.48$ & $31.77 \pm 69.13$ & $31.35 \pm 69.05$ & $149.05 \pm 47.27$ & - \\
\hline Dec & $3.53 \pm 4.49$ & $0.11 \pm 1.54$ & $-21.25 \pm 18.96$ & $-19.57 \pm 12.15$ & $-20.36 \pm 12.89$ & $-6.57 \pm 14.21$ & $2.84 \pm 56.38$ \\
Jan & $3.74 \pm 5.56$ & $4.08 \pm 3.70$ & $-2.29 \pm 54.48$ & $8.26 \pm 19.67$ & $19.24 \pm 25.51$ & $9.19 \pm 29.90$ & $9.65 \pm 41.48$ \\
Feb & $0.69 \pm 9.19$ & $3.28 \pm 8.58$ & $-25.29 \pm 70.11$ & $14.54 \pm 34.12$ & $16.73 \pm 34.54$ & $-38.14 \pm 15.95$ & - \\
\hline Mar & $5.62 \pm 6.52$ & $6.93 \pm 4.92$ & $2.38 \pm 43.40$ & $2.04 \pm 28.40$ & $4.30 \pm 19.90$ & $34.41 \pm 19.37$ & $-2.38 \pm 17.50$ \\
Apr & $-1.46 \pm 7.60$ & $-5.52 \pm 4.51$ & $-40.54 \pm 61.12$ & $-50.44 \pm 60.66$ & $-46.85 \pm 60.68$ & $-37.65 \pm 28.37$ & - \\
May & $-6.74 \pm 11.13$ & $-6.55 \pm 4.26$ & - & - & - & - & - \\
\hline Jun & $-4.21 \pm 8.50$ & $-9.59 \pm 1.93$ & - & - & - & - & - \\
\hline Mean & 0.55 & 0.44 & -11.71 & 1.09 & 3.65 & 21.54 & -14.43
\end{tabular}


TABLE VIII

CORRELATION BETWEEN THE DIFFERENT PRODUCTS DIRECTION FOR THE MONTH OF OCTOBER.

\begin{tabular}{|c|c|c|c|c|c|c|}
\hline & $\mathbf{S A R} \mathbf{R}_{r e g}$ & $\mathbf{S A R}_{D T U}$ & $\mathbf{A S C A T}_{I F R}$ & $\begin{array}{l}\text { ASCAT+ } \\
\text { SSMI }_{I F R}\end{array}$ & $\begin{array}{l}\text { SeaWinds+ } \\
\text { SSMI }_{I F R}\end{array}$ & $\begin{array}{l}\text { ASCAT+ } \\
\mathbf{S S M I} \mathbf{S}_{E O}\end{array}$ \\
\hline $\mathbf{S A R}_{C_{r e q}}$ & - & 0.61 & 0.37 & 0.38 & 0.40 & 0.31 \\
\hline $\mathbf{S A R}_{D T U}$ & 0.61 & - & 0.25 & 0.29 & 0.31 & 0.31 \\
\hline $\mathbf{A S C A T}_{I F R}$ & 0.37 & 0.25 & - & 0.56 & 0.40 & 0.23 \\
\hline $\mathbf{A S C A T}_{+} \mathbf{S S M I} \mathbf{I}_{I F R}$ & 0.38 & 0.29 & 0.56 & - & 0.58 & 0.23 \\
\hline SeaWinds+SSMI $_{I F R}$ & 0.40 & 0.31 & 0.40 & 0.58 & - & 0.22 \\
\hline $\mathbf{A S C A T}+\mathbf{S S M I} / \mathbf{S}_{E O}$ & 0.31 & 0.31 & 0.23 & 0.23 & 0.22 & - \\
\hline
\end{tabular}

this difference in location may be an artefact of the different temporal resolutions. Where the 3 days' time separation between the ingoing data in the IFREMER products and the 22 hour time separation between the $\mathrm{SAR}_{C_{\text {reg }}}$ may result in a different in location.

The yearly mean speed of $0.12 \mathrm{~m} / \mathrm{s}$ for $\mathrm{SAR}_{C_{r e g}}$ and ASCAT+SSMI $/ \mathrm{S}_{E O}$ (Table IV) are in agreement with the southward speed calculated using SAR images of 0.12 $\mathrm{m} / \mathrm{sec}$ presented in [23]. Though significantly lower then the median speed values of $0.21 \mathrm{~m} / \mathrm{s}$ presented in [9]. The yearly mean speeds for $\mathrm{SAR}_{C_{\text {low }}}$ and $\mathrm{SAR}_{D T U}$ are similar to the results for $\mathrm{SAR}_{C_{r e q}}$ and ASCAT+SSMI/S $\mathrm{S}_{E O}$ (Table IV). It should be noted that the products presented in this study are averaged over an area as well as extends further east than the traverse at $79^{\circ} \mathrm{N}$ between $15^{\circ} \mathrm{W}$ and $5^{\circ} \mathrm{E}$ in [23]. The drift speeds in [23] are higher further east than close to the Greenland coast in the west. The yearly mean speeds for the $\mathrm{ASCAT}_{I F R}, \mathrm{ASCAT}+\mathrm{SSMI}_{I F R}$ and SeaWinds $+\mathrm{SSMI}_{\text {IFR }}$ products (Table IV) are lower despite not including the lower velocity months of June until August [23].

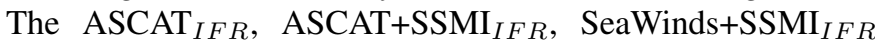
and ASCAT+SSMI $/ \mathrm{S}_{E O}$ products are not provided for the months of July to September and therefore no comparison about drift can be made for those months. This fact highlights the importance of using SAR based products for sea ice drift estimates for a full seasonal coverage. Furthermore, the summer months coincide with the peak in marine traffic rendering sea ice drift predictions especially important during these months [2].

Furthermore the present study includes an east and westward component, albeit small for most months. Whilst [23] only includes the north and southward component. The mean drift directions in Fig. $4 \mathrm{~b}$ indicate predominantly south south west to south south east drift directions. Moreover, for July to September the drift direction for the 22-26 hour time separated images are south east (Table VII). Indicating that it is important to also include the east and west component to get a complete picture of the sea ice drift.

\section{B. Time separation}

Investigating the importance of time interval on buoy drift speeds [9] showed that the longer the time interval the larger the difference. This is also seen in our study where the $\mathrm{Vel}_{48} / \mathrm{Vel}_{24}$ has a higher value than $\mathrm{Val}_{72} / \mathrm{Val}_{24}$ (Table VI). Furthermore, [10] showed that drift speed estimates derived from satellite data is affected by the time interval. For comparison the 1 hour time separated median speed values in their study are $0.21 \mathrm{~m} / \mathrm{s}$, whilst the 72 hour time separated images used in [23] indicate a mean speeds of $0.12 \mathrm{~m} / \mathrm{s}$ for the Fram Strait.

We identify two concurrent factors that affects the velocity measurement for longer time separations. First, a longer time span generates a wider diversity of ice drifting at different speeds. This speed diversity can appear for instance at a border between fast ice and marginal ice, for drifting sea ice in the presence of islands, skerries or stranded icebergs, or possibly at the ice edge where a current may grab ice sections and drag them off the pack ice. Yet another possibility is ice movement in strong eddies. For passive microwave data the drift is determined by larger structures, such as the ice edge or zones of well-defined ice concentration or ice age. This data is more suitable for linear drift than for deforming ice. Also, the drift of slow ice is difficult to determine due to the coarse spatial resolution. This will affect the speed determination and, even more heavily, the estimate of drift direction. The second factor is not related to performance but of qualitative nature; since we assume straight motion tracks between image acquisitions, we measure the air distance instead of the real travelled distance. This means that the measured speed is lower than the instantaneous speed averaged between the image acquisitions. The obvious case would be an ice floe that has travelled in a circle until it is observed the second time; it would appear as stationary even though it has had a non-zero speed. The denser sampling of the ice floe position, the higher speed would be observed.

These two effects are reflected in the mean speeds in our analysis (Fig. 4a). Comparing the mean speeds for the satellite drift products investigated here, it is evident that the mean speed decreases with longer time span. The $\mathrm{ASCAT}_{I F R}, \quad \mathrm{ASCAT}+\mathrm{SSMI} I F R$ and SeaWinds $+\mathrm{SSMI}_{I F R}$ products with a 72 hour time separation have lower speeds overall (Table IV). For ALOS at L-band, the temporal separation is normally 48 hours and the speed estimates are the lowest measured, although they are comparable to the $\mathrm{ASCAT}_{I F R}, \mathrm{ASCAT}+\mathrm{SSMI} I F R$ and SeaWinds+SSMI ${ }_{I F R}$ products for January and March. However, the mean speeds from ASCAT+SSMI/S $\mathrm{S}_{E O}$ with a 48 hour separation are comparable with the 24 hour time separated C-band SAR speed estimates. For the drift buoys used in our study, a $15 \%$ reduction in mean speed is observed when extending the time span from 24 hours to 3 days. 
The time separated C-band images presented in Fig. 4a indicate that overall the shorter time scales the higher the mean speeds. The only deviating months is the September value for the 22-26 hour time span and the February value for the above 26 hours. The months with speed values of $0.20 \mathrm{~m} / \mathrm{s}$ and above captured in the $0-22$ hours correspond to low mean velocities for the other time intervals. The higher speeds are not correlated with deviating mean drift directions (Fig. 4b). This is in agreement with studies by [5] where drift estimates using AVHRR indicate only marginal changes in the velocity field structure with changing interval from 1 day to 4 days image time separation. The months in our study for which the time separation proved important are the months of July and August. This difference in drift direction coincides with a lower proportion of very close drift ice (Fig. 5a). [17] showed that a lower sea ice concentration may affect the sea ice drift speed and [11] proved the influence on wind speed on drift speed and direction. The effect of wind on the sea ice drift direction could possibly explain the directional differences, possibly enabling more rapid changes in the sea ice drift direction.

A comparison between AVHRR data and in-situ drift buoy data conducted by [22] indicate that $71 \%$ of the drift velocities were significantly lower than those observed by buoys. In this study we observe that $\mathrm{SAR}_{C_{\text {reg }}}$ tend to underestimate the drift velocities compared to the buoy velocities (Table II). Furthermore, [22] show that the higher the buoy velocities the larger the difference between the satellite observations and the in-situ observations. This is confirmed in our study. The underestimation of drift speeds in $\mathrm{SAR}_{C_{r e g}}$ compared to the buoys is also reflected in monthly median speed ratios Table II. The buoy mean speeds are comparable to the $\mathrm{SAR}_{C_{r e g}}$ estimates apart from for November and February where the mean buoy drifts are lower (Table IV). Though studying the individual pixels closest to the buoy location indicate a good agreement between the two drift speeds.

It should be noted that the distance between the drift buoy location and the algorithm location might be as much as $10 \mathrm{~km}$ and the algorithm is an average values over $1.5 \times 1.5 \mathrm{~km}^{2}$. We observe a slight negative trend with distance. Though there is no significant change in the monthly mean speed values and the monthly median speed ratio when the distance is set to between 10 and $20 \mathrm{~km}$. When the distance exceeds $20 \mathrm{~km}$ the median speed ratio values lowers however the mean speed values are similar.

Statistical analyses on drift buoy trajectories in the study region indicate that $\mathrm{Vel}_{48} / \mathrm{Vel}_{24}$ is 0.91 (see Table VI). Given changes in wind and currents the values are expected to be below 1. The mean monthly speed ratio of the 48 hour time separated ASCAT+SSMI/ $\mathrm{S}_{E O}$ and the 22 hour time separated $\mathrm{SAR}_{C_{\text {reg }}}$ gives a ratio of 0.96 . Indicating that the ASCAT+SSMI/S $E O$ mean monthly speeds are higher than expected from the smoothing of the buoy data. The IFREMER product ratios range between 0.73 (ASCAT ${ }_{I F R}$ ) to 0.77 (SeaWinds $\left.+\mathrm{SSMI}_{I F R}\right)$. This is lower than the corresponding buoy speed ratio (Table VI).

\section{Differences in spatial resolution}

The difference median speed ratio between $\mathrm{SAR}_{D T U} / \mathrm{SAR}_{C_{\text {reg }}}$ and $\mathrm{SAR}_{D T U} / \mathrm{SAR}_{C_{\text {low }}}$ are small as well as have high correlation values (Table III). The $\mathrm{SAR}_{C_{\text {low }}}$ has a lower std than the regular product for the median speed ratio. $\mathrm{SAR}_{C_{\text {low }}}$ has lower mean speeds than $\mathrm{SAR}_{C_{r e g}}$ possibly indicating that smaller scale high speed features are not resolved at the lower spatial resolution but included in $\mathrm{SAR}_{C_{r e g}}$. [10] also showed that the high sea ice drift in the Fram Strait is significantly underestimated using satellite data with a grid spacing of more than 31.2 $\mathrm{km}$. This implies that the higher original spatial resolution of $\mathrm{SAR}_{C_{\text {reg }}}$ is needed should one wish to study smaller scale features. This is in agreement with the findings in our study, e.g. the lower monthly mean speeds (Table IV) for the lower spatial resolution products. Moreover, the monthly mean directional differences (Table VII) indicate larger difference between the SAR based products and the $\mathrm{ASCAT}+\mathrm{SSMI} / \mathrm{S}_{E O}, \quad \mathrm{ASCAT}_{I F R}, \quad \mathrm{ASCAT}+\mathrm{SSMI}_{I F R}$ and SeaWinds $+\mathrm{SSMI}_{I F R}$ products. Specifically the std values are high. The ASCAT $+\mathrm{SSMI} / \mathrm{S}_{E O}$ product on average is more in agreement with the $\mathrm{SAR}_{C_{r e g}}$ than the corresponding $\mathrm{ASCAT}_{I F R}, \quad \mathrm{ASCAT}+\mathrm{SSMI} I F R$ and SeaWinds+SSMI $I_{I F R}$ products, possibly indicating that the temporal resolution is more important than the spatial resolution for capturing the sea ice drift patterns in the Fram Strait.

For the comparisons with the ASCAT+SSMI $/ \mathrm{S}_{E O}$, $\mathrm{ASCAT}_{I F R}, \quad \mathrm{ASCAT}+\mathrm{SSMI} I F R$ and SeaWinds $+\mathrm{SSMI}_{I F R}$ products the $\mathrm{SAR}_{C_{r e g}}$ is downsampled to the same grid system. One may speculate whether the low values on the ice drift determined from radiometer and scatterometer data (Table IV) is simply an effect of the temporal sampling, or if the spatial sampling is a factor. The latter could be the case if we are tracking distinguished zones of discrete ice concentration levels instead of individual floes or flow parcels. Considering the ocean as a dispersive medium, there would be a phase velocity attributed to each ice floe depending on its size (corresponding to wavelength), whereas the measured drift in the case of radiometer and scatterometer data would correspond to the group velocity.

The effect of the lower spatial resolution can be observed in the sea ice margin where the outermost drift vectors in the transition zone between open water and sea ice often are noise-like and hence may be removed by the quality control check in place in e.g. the algorithm for $\mathrm{SAR}_{D T U}$. A lower resolution may therefore imply that a wider area is affected by such noise and hence the marginal ice zone may be affected. Other transitions zones such as the one between first-year and multi-year ice will generally have less erratic drift and can therefore be better captured despite being narrower.

\section{Seasonal drift comparison}

The sea ice drift has a seasonal dependency where the summer months are characterised by lower drift velocities than the winter months [23]. The underlying mechanism behind the slow summer ice is a reduction of the north-south pressure gradient and therefore also the wind-driven component of the 
ice drift becomes insignificant [28]. We observe that the drift velocities for the C-band SAR estimates are lowest during the summer months (Table IV) which is also in agreement with the 2004-2010 average speed values presented in [23]. A seasonal dependency was observed by [23] using SAR data. This is in line with our results; the months of December to March were observed to have higher velocities than the other months. The radio-and scatterometer data did not show the same tendency with higher velocities for these months (cf IV). This may be an artefact of the longer time separation or the lower spatial resolution. Though the SAR estimated summer velocities presented in this study are higher than those measured by [23] and the winter velocities are lower. The higher summer velocities may be explained by the fact that study area used in [23] extends further west than our study. [23] observed the lowest velocities along their transect in the western part.

Results by [14] indicate that L-band based drift estimates are superior to C-band image estimates. However, inclusion of large proportions of multi-year ice or open ice with less than $30 \%$ sea ice might affect these results (Fig. 5). Moreover, drift speeds in [23] are higher further east than close to the Greenland coast in the west. This combined with the longer time separation between the L-band than the C-band satellite images may explain the lower drift speed velocities observed in the L-band product. Nonetheless, L-band SAR is a useful tool to complement existing C-band SAR drift speed estimates.

\section{CONCLUSION}

In this study we show that high temporal and spatial resolution is important to accurately estimate the sea ice drift in the Fram Strait. We show that higher temporal resolution in SAR images corresponds to higher sea ice drift speeds. This is true both for comparisons with other temporal resolution for the SAR images and in comparison between SAR based and radar- and scatterometer products. The drift direction differences is most affected by the spatial resolution as seen in the difference in direction between the SAR products and the radar- and scatterometer products. Moreover, we show a relationship between the satellite image time span and the captured drift speed where higher drift speeds are identified when the time span is smaller. A smaller time span is less important during the summer months due to the lower drift speeds during the summer. The drift estimates, covering over many seasons, indicate that the SAR based products have more of a seasonal dependency with higher drift speeds during the winter compared to the other seasons. This trend is not evident in the radar scatterometer and radiometer data products. Furthermore, it is apparent that L-band data carry complementary information compared to both C-band SAR and radiometry products. The L-band is in theory highly beneficial during the summer due to higher penetration into wet snow, but limitations in study area and data volume for the L-band data prohibit such conclusions.

\section{ACKNOWLEDGMENT}

This work has been funded by the Swedish National Space Board and Chalmers Area of Advance Transport. Data from
Envisat and ALOS were provided by the European Space Agency within the framework of the proposals Sea ice measurements with Cryosat-2 and SAR (AO 6533) and Evaluation of Sea and Sea-ice state information for Improved Maritime Security ESSIMS (AO 5760). Sea ice displacement data was kindly provided by Roberto Saldo, DTU Space, Technical University of Denmark. EUMETSAT and IFREMER are acknowledged for their services providing us with ice drift products.

\section{REFERENCES}

[1] A. Berg and L. E.B. Eriksson, Investigation of a Hybrid Algorithm for Sea Ice Drift Measurements Using Synthetic Aperture Radar Images, IEEE Trans. Geosci. Rem. Sens., 52(8), 5023-5033, 2014, doi:10.1109/TGRS.2013.2286500.

[2] L. W. Brigham, The fast-changing maritime Arctic, U.S. Naval Institute Proceedings, 136(5): 54-59, 2010.

[3] W. Dierking and L.T. Pedersen, Monitoring sea ice using Envisat ASAR A new era starting 10 years ago, Proc. IEEE IGARSS, 1852-1855, 2012.

[4] W. Dierking and T. Busche, Sea ice monitoring by L-band SAR: An assessment based on literature and comparisons of JERS-1 171 and ERS-1 imagery, IEEE Trans. Geosci. Rem. Sens., 44(4), 957-979, 2006, doi:10.1109/TGRS.2005.861745.

[5] W. Emery, C. Fowler, J. Hawkins and R. Preller, Fram Strait satellite image-derived ice motions, J. Geophys. Res., 96, 4751- 4768, 1991, doi:10.1029/90JC02273.

[6] R. Ezraty, F. Girard-Ardhuin and J. Poill, Sea Ice Drift In The Central Arctic Estimated From SeaWinds/QuikSCAT Backscatter Maps, Users Manual, Version 2.2, February 2007.

[7] F. Girard-Ardhuin and R. Ezraty, Enhanced Arctic Sea Ice Drift Estimation Merging Radiometer and Scatterometer Data, IEEE Trans. Geosci. Rem. Sens., 50(7), 2639-2648, 2012, doi:10.1109/TGRS.2012.2184124.

[8] J. Haarpaintner, Arctic-Wide Operational Sea Ice Drift From Enhanced-Resolution QuikScat/SeaWinds Scatterometry and Its Validation, IEEE Trans. Geosci. Rem. Sens., 44(1), 102-107, 2006, doi:10.1109/TGRS.2005.859352.

[9] M. Haller, B. Brümmer, and G. Müller, Atmosphereice forcing in the transpolar drift stream: results from the DAMOCLES ice-buoy campaigns 2007-2009, The Cryosphere, 8, 275-288, 2014, doi:10.5194/tc-8-2752014.

[10] B. Hwang, Inter-comparison of satellite sea ice motion with drifting buoy data, Internat. J. Rem. Sens., 34(24), 8741-8763, 2013, doi: $10.1080 / 01431161.2013 .848309$.

[11] N. Kimura and M. Wakatsuchi, Relationship between sea-ice motion and geostrophic wind in the northern hemisphere, Geophys. Res. Letters, 27(22), 3735-3738, 2000, doi:10.1029/2000GL011495.

[12] R. Kwok, A. Schweiger, D.A. Rothrock, S. Pang, and C. Kottmeier, Sea ice motion from satellite passive microwave imagery assessed with ERS SAR and buoy motions, J. Geophys. Res., 103(C4), 8191-8214, 1998, doi: $10.1029 / 97 \mathrm{JC} 03334$.

[13] T. Lavergne and S. Eastwood, Low Resolution Sea Ice Drift Product Users Manual, GBL LR SID OSI 405, Version 1.6, November 2013.

[14] J. Lehtiranta, S. Siiriä, and J. Karvonen, Comparing C- and L-band SAR images for sea ice motion estimation, The Cryosphere, 9, 357-366, 2015, doi:10.5194/tc-9-357-2015.

[15] Leppäranta, The Drift of Sea Ice, 380 pp., Springer-Verlag Berlin and Heidelberg GmbH Co. K, 2011.

[16] http://nsidc.org/arcticseaicenews/, Accessed 2014-12-29.

[17] E. Olason and D. Notz, Drivers of variability in Arctic sea-ice drift speed, Journal of Geophysical Research: Oceans, 119, 5755-5775, 2014, doi: 10.1002/2014JC009897.

[18] B.S. Otieno, An Alternative Estimate of Preferred Direction for Circular Data, Ph.D Thesis, Virginia Polytechnic Institute and State University, 2002.

[19] P. Rampal, J. Weiss and D. Marsan, Positive trend in the mean speed and deformation rate of Arctic sea ice, 1979-2007, J. Geophys. Res., 114, C05013, 2009, doi:10.1029/2008JC005066.

[20] B. Rudels, H.J. Friedrich and D. Quadfasel, The Arctic circumpolar boundary current, Deep-sea Research Part II: Topical Studies in Oceanography, 46, 1023-1062, 1999, doi:10.1016/S0967-0645(99)00015-6.

[21] R. Saldo, Sea Ice activities at DTU Space, Presentation at Nordic Sea Ice RS Workshop 2011, Gothenburg, Sweden 
[22] S. Schwegmann, C. Haas, C. Fowler, and R. Gerdes, A comparison of satellite-derived sea ice motion with drifting buoy data in the Weddell Sea, Ann. Glaciol., 52, 103-110, 2011, doi:10.3189/172756411795931813.

[23] L.H. Smedsrud, A. Sirevaag, K. Kloster, A. Sorteberg, and S. Sandven, Recent wind driven high sea ice area export in the Fram Strait contributes to Arctic sea ice decline, The Cryosphere, 5, 821-829, 2011, doi:10.5194/tc-5-821-2011.

[24] G. Spreen, R. Kwok, and D. Menemenlis, Trends in Arctic sea ice drift and role of wind forcing: 1992-2009, Geophysical research letters, 38, L19501, 2011, doi:10.1029/2011GL048970.

[25] Product User Manual for global high resolution SAR sea ice drift, Issue 2.3, May 2014.

[26] Product User Manual for Arctic time series of ice drift, Issue 2.2, November 2014

[27] Product User Manual for global sea ice concentration, edge, type and drift, Near real time observations, Issue 1.4, July 2014.

[28] T. Vinje, Fram Strait Ice Fluxes and Atmospheric Circulation: 19502000, Journal of Climate, 14, 3508-3517, 2001, doi:10.1175/15200442(2001) $014<3508$ :FSIFAA $>2.0$. CO 2 .

[29] Y. Zhao, A.K. Liu, and D.G. Long, Validation of sea ice motion from QuikSCAT with those from SSM/I and buoy, IEEE Trans. Geosci. Rem. Sens., 40(6), 1241-1246, 2002.

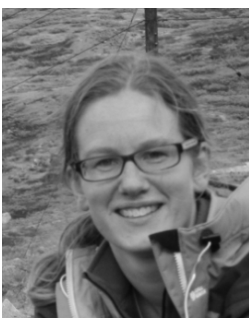

A. Malin Johansson received an M.Sc. in physical oceanography from Gothenburg University, Sweden, in 2005. She received the Ph.D. degree in physical geography remote sensing from Stockholm University, Sweden, in 2012. She was a Postdoctoral Researcher in the Radar Remote Sensing group at Chalmers' Department of Earth and Space Sciences. She is currently working as a Postdoctoral Researcher at University of Troms $\varnothing$ - The Arctic University of Norway. Her research interests include remote sensing of sea ice using spaceborne SAR.

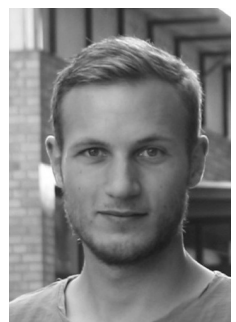

Anders Berg received the M.Sc. degree in Engineering Physics and the Ph.D. degree from the Chalmers University of Technology, Gothenburg, Sweden, in 2008 and 2014, respectively. He is currently working as a Postdoctoral Researcher in the Radar Remote Sensing group at Chalmers' Department of Earth and Space Sciences. His research interests include remote sensing of sea ice using spaceborne SAR and radar altimetry. 